\title{
Earnings Guidance after Regulation FD
}

\author{
By \\ Ronen Feldman \\ Data Mining Laboratory \\ Computer Science Dept. \\ Bar-Ilan University \\ Ramat-Gan, ISRAEL 52900 \\ feldman@cs.biu.ac.il
}

Ron Lazer and Joshua Livnat

Department of Accounting

Stern School of Business Administration

New York University

311 Tisch Hall

$40 \mathrm{~W} .4^{\text {th }} \mathrm{St}$.

NY NY 10012

(212) $998-0022$

rlazer@stern.nyu.edu

jlivnat@stern.nyu.edu

First Draft: February 2003

Current Draft: April 9, 2003

The authors acknowledge the access to data provided by Factset Information Services, Inc., and the assistance of Scott Starkin. The authors also gratefully acknowledge the contribution of Clearforest (www.clearforest.com) for providing access to the ClearResearch and ClearTags platforms. 


\title{
Earnings Guidance after Regulation FD
}

\author{
$\underline{\text { Abstract }}$ \\ This study investigates market reactions to voluntary earnings guidance provided \\ by managers after the enactment of Regulation FD, which requires companies to \\ disseminate material news to all investors simultaneously. More managers now issue \\ their guidance to the public instead of disclosure to a selective group of analysts, in \\ conformity with Regulation FD. We examine a very large set of earnings guidance \\ disclosures based on identification of these announcements using text mining techniques. \\ Our results indicate that guidance provided with the disclosure of earnings is not \\ associated with significant market reactions, but guidance provided between earnings \\ releases is associated with significant negative reactions. We further show that market \\ reactions are consistent with the trend implied by management even when it is in the \\ form of qualitative disclosure. Finally, we show that market reactions are stronger (more \\ negative, typically) for NASDAQ firms than NYSE or AMEX firms, larger firms, and \\ when the disclosure involves revenues and not earnings.
}




\section{Earnings Guidance after Regulation FD}

Regulation FD was supposed to change the way publicly-listed companies release information to market participants. If in the past managers could disclose their assessments and forecasts of future results to selected groups of analysts, under the new rules all material information must be disclosed to the public simultaneously. As a result, and concurrently with the development of webcasts, many companies began opening their conference calls to the public, so some of the information about future events and management expectations is reported to all potential investors who choose to listen in. Furthermore, many managers have begun issuing public guidance to the market in press releases, consistent with the requirements of Regulation FD, although companies vary considerably in the manner and timing of earnings guidance.

The purpose of this study is to examine earnings guidance practices of companies after Regulation FD and their associated effects on stock returns. In particular, this study investigates whether market reactions differ among earnings guidance that occurs at the time of the preliminary earnings announcements and those that occur outside the earnings announcements. The study also compares the effects of earnings guidance on stock returns for companies with different market capitalizations and exchange listing; presumably, smaller companies are less closely followed by analysts and management's guidance may be more effective in changing investors' assessments and consequently prices. Finally, we examine whether investors react differently to guidance about earnings and revenues. 
To examine a large sample of earnings guidance disclosures, we use a text-mining approach to identify such announcements from press releases issued by companies. Text mining is similar to data mining, except that it relates to analysis of text documents using linguistic rules, instead of the typical analysis of numerical data typical to data mining. Using text mining, we are able to identify over 3,400 earnings guidance disclosures during the period October 2000 through July 2002. Most studies to date have used substantially smaller samples, as described below.

The results of this study indicate that market participants react negatively to earnings guidance that occurs between earnings releases, consistent with the intuition that these types of voluntary disclosures are generally negative in nature, warning investors that future prospects are worse than previously expected. In contrast, earnings guidance provided with the earnings release (or up to three days afterwards) is unassociated with abnormal returns. Our results show that even when the guidance is set qualitatively, i.e., by indicating that earnings will be higher (lower), market participants react by increasing (decreasing) prices significantly. We further show that reactions are stronger (more negative) to announcements made by NASDAQ firms (as compared to NYSE or AMEX firms), but are weaker for smaller companies than for larger companies. ${ }^{1}$ Finally, market reactions seem more pronounced to revenue disclosures than to earnings disclosures, possibly because managers who wish to forewarn investors about deteriorating conditions do so more often in terms of revenues than earnings.

\footnotetext{
${ }^{1}$ Given the deteriorating economic conditions, the period we study is characterized by mostly negative earnings guidance.
} 


\section{Institutional Setting and Prior Research}

Some companies find it valuable to provide market participants guidance about revenues, earnings, earnings per share, or some other measure of profit (such as operating profit). Note that this is voluntary disclosure; management has no responsibility to preannounce their expectations about future operations to investors. They are likely to do so if the benefits of this disclosure exceed the costs of the disclosure. In particular, managers who possess negative information about future financial results may provide guidance to lower levels of expectations in an attempt to reduce expected payouts in law suits brought against them, claiming they had material negative information which had not been timely released to the market. Some companies provide guidance consistently, whereas others do so occasionally or rarely. The restrictions imposed on private dissemination of guidance by Regulation FD are likely to cause an increase in the frequency of earnings guidance provided by companies. ${ }^{2}$ Let us examine two examples of earnings guidance announcements.

\section{Example 1:}

On Oct. 17, 2000 Intel Corp. ("Intel") announced record results for the third quarter of 2000 and revised its outlook publication procedures in connection with the adoption of Regulation FD. Intel said it would keep its Outlook forward-looking statements and risk factors statements publicly available on its web site. Towards the end of each fiscal quarter, it would have a "Quiet Period" when it would not update Outlook, but prior to the start of the Quiet Period, the public can continue to rely on the Outlook

\footnotetext{
${ }^{2}$ One of the authors, Ron Lazer, is currently investigating this issue in another study.
} 
as reflecting Intel's most current expectations. The Quiet Period extends to the day when Intel's next quarterly earnings release is published. Six months later, On April 17, 2001 Intel announced that "Beginning this quarter (second quarter, 2001) Intel will have a mid-quarter Business Update to the Outlook provided...". Currently, during Intel's earnings quarterly press releases, Intel also announces the date for its mid-quarter update. On July 17, 2001 Intel announced the results for the second quarter of 2001 and its business outlook for the third quarter of 2001: "Revenue in the third quarter of 2001 is expected to be between $\$ 6.2$ billion and $\$ 6.8$ billion." In addition, Intel announced that it "plans to provide a mid-quarter Business Update to the Outlook provided below on Sept. 6." On Sept. 6, 2001 Intel announced the mid quarter update, stating it "expects revenue for the third quarter to be within the previous expectation and slightly below the midpoint of the range provided on July 17." The release included updates regarding other expenses and capital expenditures. Thus, Intel provides systematic forecasts with the earnings release, and an update between earnings releases with a known date for the update.

\section{Example 2:}

On Oct. 29, 2001 FedEx Corp. ("FedEx") updated its earnings outlook for the second quarter, ending Nov. 30, 2001. In its press release, FedEx announced it "expects to earn 40 cents to 45 cents a share excluding its slice of the aid package and 61 cents to 66 cents a share including the \$101 million in government assistance." On Dec. 19, 2001 FedEx reported the results for the second quarter (ending Nov. 30, 2001). Earnings per share (not included the compensation from the Air Transportation Safety and System Stabilization Act) were 57 cents per share. In its press release, FedEx also included 
earnings forecasts for the third and the fourth quarters: "we now expect earnings for the third quarter to be $\$ 0.25$ to $\$ 0.35$ per diluted share, and earnings for the fourth quarter to be $\$ 0.70$ to $\$ 0.80$ per diluted share. "The first announcement on October 29, 2001 occurred between earnings announcement and was intended to provide investors with a profit warning. The second guidance coincided with the earnings announcement. Unlike for Intel, investors could not have anticipated when the first announcement would be made, if at all.

These two examples show that companies differ in their earnings guidance practices along the following dimensions (i) what is the metric used (revenues for Intel and EPS for FedEx), (ii) when is it disclosed (with the release of earnings or afterwards) (iii) whether it is scheduled or comes as a surprise and (iv) whether a quantitative disclosure is made or just a qualitative one.

\section{Prior Research:}

Prior research has generally focused on the motivation for companies' preannouncements, and on the market reaction to these pre-announcements. Soffer, et al, (2000) examine the factors influencing the decision of a firm to voluntarily accelerate the release of earnings via a "pre-announcement". They find that firms are more likely to preannounce earnings if the consensus of analyst' forecasts is very different from actual earnings, if the dispersion of these forecasts is high, and if the firm has negative news. Skinner (1994) argues that managers pre-announce to prevent lawsuits caused by large stock price declines at the bad earnings announcement, and to protect their reputation with analysts and institutional investors by not delaying bad news. Using a random sample of 93 NASDAQ firms during 1981-90, he finds that earnings-related voluntary 
disclosure occur infrequently (on average, one disclosure for every ten quarterly earnings announcements), and that good news disclosures tend to be point or range estimates of annual earnings-per-share, whereas bad news disclosures tend to be qualitative statements about the current quarter's earnings. In his sample, quarterly earnings announcements that convey large negative earnings surprises are preempted about $25 \%$ of the time by voluntary corporate disclosures while other earnings announcements are preempted less than $10 \%$ of the time.

Kasznik and Lev (1995) look at management's discretionary disclosures for firms that subsequently experience large earnings surprises. They find that less than $10 \%$ of their large-surprise firms published quantitative earnings or sales forecasts (less than 100 firms), and $50 \%$ provide no earnings guidance, although they subsequently report very significant earnings surprises. Coller and Yohn (1997) use a sample of 278 quarterly earnings forecasts, including point estimates, range estimates, and upper and lower bound estimates, to examine whether the decision to issue a management earnings forecast is related to information asymmetry in the market for the firm's stock, and whether the forecasts reduce the information asymmetry. They find support to the view that managers release forecasts to reduce information asymmetry.

Miller (2001) examines a sample of 80 companies experiencing an extended period of seasonally adjusted earnings increases. Using 416 observations of forecasts and earnings pre-announcements over a period of 3 years, he finds an increase in disclosure during the period of increased earnings. The increase tends to be bundled with earnings announcements, and the market responds positively to this disclosure. 
Johnson, Kasznik and Nelson (2001) use 1135 forecasts for about 600 firms in high litigation risk industries made during 1994 and 1996, to evaluate corporate voluntary disclosure of forward looking information under the Safe Harbor provision of the Private Securities Litigation reform Act of 1995. They find that managers engage in more disclosure after the rule enactment, and that the increase in disclosure is an increasing function of the firms' ex-ante risk of litigation.

Heflin, Subramanyam and Zhang (2003) examine voluntary disclosure after the implementation of Regulation FD and find (a) lower return volatility around earnings announcements; (b) some improvement in the speed with which the price before the earnings announcement converges to its post announcement level; (c) no reliable evidence of changes in various aspects of analysts forecast bias, accuracy, and dispersion; and (d) an increase in the quantity of firms' voluntary forward looking disclosures.

Skinner (1994) shows that there is substantially stronger market reaction to negative news guidance (-6.1\%) compared with positive news (2.5\%). Kasznik and Lev (1995) show that the market-adjusted return around in the five-day window around the earnings (sales) forecast was about $5.4 \%$ for positive news and about $-5.3 \%$ for negative news. Furthermore, they show that for the companies with negative disclosures, the total market-adjusted return in the five-day window around the warning and the five-day window around the subsequent earnings release was significantly more negative than companies which provided no warnings before releasing significant negative decline in earnings.

Soffer et al (2000) show that size-adjusted returns in the three-day window surrounding the earnings guidance disclosure is significantly associated with the surprise 
in the announcement relative to analysts' forecasts prior to the announcement, and is about $6.95 \%$ stronger (more negative) for negative guidance. However, they also show that negative guidance announcements tend to preempt the entire negative news that are subsequently disclosed in the earnings release, but only about $50 \%$ of the subsequent positive news are reported by companies providing positive guidance. They also show that trading based on the fact that positive guidance is likely to be followed by even greater positive surprise subsequently can be a profitable strategy, earning about $2.6 \%$ size-adjusted returns, or even $3.4 \%$ in companies in high litigation industries.

Thus, it is expected that companies provide earnings guidance to preempt future surprises, and would do so in greater intensity when litigation risk is high or when there are greater information asymmetries between investors and managers or other parties. We further expect that earnings guidance is associated with significant market reactions around the announcement date.

\section{Text Mining and the Ability to Identify Earnings Guidance}

Text mining is a new area of research and application that addresses the information overload problem (see e.g., Feldman and Dagan, 1995, Feldman and Hirsh, 1996, and Feldman et al, 1997). It uses techniques from the general field of data mining to process text documents, extract relevant information from these documents, and provide the user with this information using reports or graphical representations. The application described in this study processed all the text documents of Comtex (www.comtex.com), which collects news articles from many sources, most importantly for our study from PR 
Newswire and Business Wire. The text mining application we use identified those documents that included earnings guidance for publicly-listed companies, and was used to form our sample.

A typical Text Mining system begins with collections of raw documents, without any labels or tags. Documents are first automatically tagged by Categories, Terms and Relationships extracted directly from the documents. Next, extracted Categories, Entities and Relationships are used to support a range of data mining operations on the documents. Text categorization is concerned with partitioning a large collection of documents into subsets that are interrelated by some pre-defined criteria. For instance, the Yahoo web-browser categorizes the whole web into areas such as "News and Media", "Science", "Arts" etc. Each document in this large collection is tagged by words characteristic of categories, which enables the association of the document (or web-site) with its relevant categories. Limiting the set of documents for mining to certain relevant sub-categories makes the follow-up tasks easier for the mining tools, and increases the likelihood that these tools will extract the most on-target bits of information from the text. The actual detection of facts within the text is typically performed through information extraction methods.

Information extraction is performed by combining natural language processing tools, lexical resources and semantic constraints (see, e.g., Cardie, 1997, Cowie and Lenhart, Feldman et al 2000, 2001, 2002, and Leek, 1997). Complementary visualization tools enable the user to explore, check (and correct if required) the results of the process effectively. As a first step in tagging documents, each document is processed to find (extract) Entities and Relationships that are likely to be meaningful and content-bearing. 
In "Relationships" we refer to Facts or Events involving certain Entities. A possible "Event" may be that a company has entered into a joint venture or released its earnings. A "Fact" may be that a person is employed by a specific company in a specified position. The extracted information provides more concise and precise data for the mining process than the more naive word-based approaches such as those used for text categorization, and tends to represent concepts and relationships that are more meaningful and relate directly to the examined document's domain. Consequently, the information extraction methods allow for mining of the actual information present within the text, rather than the limited set of tags associated with the documents. Using the information extraction process, the number of different relevant Entities and Relationships on which the data mining is performed is unbounded, typically thousands or even millions, far beyond the number of tags which any automated categorization system could handle.

\section{Text Mining for Earnings Guidance:}

To identify cases of earnings guidance, we use the following rules which search for specific patterns that involve the identification of certain elements in a document. Let us show several examples of such patterns ${ }^{3}$ :

\section{Pattern1: ResultsPhrase FinancialQuarter [ FinancialAmount ] Trend Expectations}

Example: "Akorn, Inc. (Nasdaq: AKRN) today announced that earnings for the quarter ending September 30, 2000 will be significantly below expectations"

ResultsPhrase : earnings

FinancialQuarter : the quarter ending September 30, 2000

Trend : will be significantly below

Expectations : expectations

\footnotetext{
${ }^{3}$ Text in square brackets indicates an element that is optional and may not necessarily appear in the specific document.
} 


\section{Pattern2: FinancialQuarter ResultsPhrase FinancialAmount Trend Expectations}

Example: "INTERLINQ Software Corporation (Nasdaq:INLQ) today announced that it anticipates first-quarter revenue will fall below the company's expectations."

FinancialQuarter : first-quarter

ResultsPhrase : revenue

FinancialAmount :

Trend : will fall below

Expectations : the company's expectations

Example: "Drypers Corporation (Nasdaq: DYPR) today announced that its third quarter revenues and earnings will fall below expectations."

FinancialQuarter : third quarter

ResultsPhrase : revenues and earnings

FinancialAmount :

Trend : will fall below

Expectations : expectations

\section{Pattern3: Expectations ResultsPhrase FinancialAmount FinancialQuarter [ Trend ]}

Example: "The Company expects earnings per share to be approximately $\$ 0.04$ per share for the third quarter."

Expectations : The Company expects

ResultsPhrase : earnings

FinancialAmount : \$0.04 per share

FinancialQuarter : third quarter

Example: "Featherlite, Inc. (Nasdaq: FTHR), a leading manufacturer and marketer of specialty aluminum trailers and luxury motorcoaches, said today it expects to report a net loss of 10 cents per diluted share for its third quarter ended Sept. 30, which is below previous expectations"

Expectations : it expects

ResultsPhrase : net loss

FinancialAmount : 10 cents per diluted share

FinancialQuarter : third quarter ended Sept. 30

Trend: which is below previous expectations 


\section{Pattern4: ResultsPhrase Trend FinancialQuarter FinancialAmount}

Example: "Sawtek, which is being acquired by Triquint, also said it sees weaker profit ahead due to a slowdown in the wireless-communications sector"

ResultsPhrase : profit

Trend: weaker

FinancialQuarter : ahead

FinancialAmount :

These and similar rules are used by the text mining software to identify earnings guidance. However, the system may yield announcements that are not necessarily earnings guidance, nor is the software likely to identify all guidance announcements. Thus, we need to impose additional restrictions to ensure that identified announcements are indeed earnings guidance announcements.

\section{$\underline{\text { Additional Filters: }}$}

During the period October 2000 through July 2002, we identified 16,026 documents that were classified as earnings guidance announcements of companies that were traded on the NYSE, AMEX or NASDAQ. Analysis of a sub-sample of these announcements led us to put some restrictions on the text mining results to ensure that the announcements indeed related to earnings guidance. We have classified an announcement as earnings guidance if it related to a quarter beyond the most recently announced quarter, or to a year beyond the current year. We further classified an announcement as earnings guidance if the text mining rules extracted the trend from the announcement, i.e., whether the item was expected to be "Higher", "Lower", or "Unchanged". Finally, we classified an announcement as earnings guidance if the text mining rules extracted a range for the amount, e.g., $\$ 640-\$ 660$ million (in revenues). These restrictions resulted in 
7,392 announcements that were identified as earnings guidance disclosures. ${ }^{4}$ We further deleted any earnings guidance announcement that was within three days of an earlier announcement of earnings guidance for the same company. This reduced the sample to 4,460 announcements, which were further reduced to 3,459 announcements for which we could obtain size-adjusted returns from the price database maintained by Factset Information Services, Inc. This last set of announcements is the sample that is used in the remainder of this study. Note that this is a very large set of earnings guidance announcements. Most prior studies used much smaller samples, typically less than 500 announcements.

\section{Results}

The sample consists of 3,495 announcements made by 1,788 distinct firms, with mean (median) market capitalization at the end of 2001 of $\$ 4,809$ (\$430) million. Thus, the sample companies are representative of the mid-cap to large-cap sectors of the market, although more than $25 \%$ of the announcements are issued by firms with market capitalization below $\$ 100$ million on 12/31/2001. Table 1 reports the frequencies of the number of announcements by firms and the median market value as of $12 / 31 / 2001$. As can be seen in the table, over $50 \%$ of the companies in our sample have only one announcement identified as earnings guidance, although they may have other such announcements that we have not identified and included in our sample. There is a clear correlation between the number of announcements captured in our sample and the market

\footnotetext{
${ }^{4}$ It is entirely possible that announcements identified as earnings guidance but not included in our sample were also in fact earnings guidance announcements.
} 
capitalization of a company; larger firms have typically more appearances in our sample. The largest numbers of announcements in our sample are made by (in descending order) Intel, Microsoft, Yahoo, and Nortel.

(Insert Table 1 about here)

Table 2 reports the distribution of firms in the various 2-digit SIC industries. The table lists only those industries with at least 18 firms (above 1\%) of all companies in our sample. As can be seen in the table, there is a reasonably uniform distribution across industries, except for concentrations in the software industry (73, 22.3\%), electronics (36, $11.7 \%)$, machinery and computer equipment $(35,8 \%)$, measuring instruments $(38,5.7 \%)$, and chemicals $(28,5.4 \%)$. These are likely to be the industries that have suffered most from the economic downturn during the sample period, which probably led to many earnings warnings issued by companies.

(Insert Table 2 about here)

Table 3 reports the size-adjusted returns for the three-day window centered on the announcement date. To calculate size-adjusted returns, we first calculate the three-day cumulative return for the announcing firm. Based on its market capitalization of equity (size) at the end of the previous quarter, we assign it to one of ten portfolios ranked on size. We calculate the equally-weighted three-day cumulative return for all companies in the same size decile as the announcing firm, and subtract this return from the announcing firm's return. The table shows that the average preannouncement is associated with a negative size-adjusted return of $2.9 \%$, which is significantly different from zero at a level below 0.001 . This is consistent with prior research, intuition, and our knowledge about economic conditions during the sample period, which were deteriorating for most 
companies, and were associated with negative news during the guidance period. Note, however, that not all announcements were treated by the market with the same force companies providing guidance during the earnings release period (i.e., within three days of the earnings release date) had a negative average size-adjusted return of $0.5 \%$, which is not significantly different from zero. In contrast, those announcements that occurred between earnings release dates were associated with an average negative size-adjusted return of $4.7 \%$, significantly different from zero at a level below 0.001 . Thus, on balance, announcing firms had negative size-adjusted returns, but more so if these announcements were not made during the earnings release period.

(Insert Table 3 about here)

Table 4 reports size-adjusted returns for announcements that indicated trend in earnings (or revenues, or any other metric used), and typically did not include any quantitative guidance as well. There were a total of 949 cases where a trend was indicated, with 323 announcements indicating a higher trend, 515 a lower trend, and 111 indicating unchanged trend. The table reports the mean size-adjusted returns for each of these categories. It clearly shows that the market reacted positively and significantly to announcements of a higher trend, negatively and significantly to announcements of a lower trend, and insignificantly different from zero for those announcements that reported an unchanged trend. Thus, market participants reacted significantly and in the right direction to these qualitative disclosures.

(Insert Table 4 about here)

Table 5 is similar to Table 4 but splits the trend announcements into those that were made between earnings releases (stand-alone announcements), and those that were 
within three days of the earnings release. As can be seen, positive announcements and negative announcements are associated with significant returns in the same direction, when these announcements are made outside the usual earnings releases. In contrast, only negative announcements are associated with significant negative returns when the guidance is provided within three days of the earnings release. Positive guidance provided with the earnings announcement causes no significant return. Consistent with Table 4, announcements that indicated unchanged trend did not cause any significant return whether between earnings announcements or with earnings releases.

(Insert Table 5 about here)

Table 6 shows the size-adjusted returns by exchange listing and separately for announcements made between earnings releases and guidance provided with the earnings release. As can be seen from the table, the mean size-adjusted return is typically more negative for NASDAQ-listed companies than the reaction to the announcements made by NYSE or AMEX companies. This may be explained by the richer information environment for NYSE and AMEX companies, which implies that company announcements and guidance may have been anticipated to a greater extent by market participants, and therefore caused a weaker reaction.

\section{(Insert Table 6 about here)}

Table 7 reports information about the size-adjusted returns of companies sorted by market capitalization at the end of the previous quarter (size). Panel A reports the average return for all announcements, whereas Panel B reports the returns separately for announcements made between earnings releases and those with earnings releases, after aggregating deciles to obtain sufficient number of observations. As can be seen from the 
table, typically, larger companies have more negative market reactions to their earnings guidance than smaller firms. This is particularly noticeable for announcements made between earnings releases and deciles $7-10$, where the reaction is insignificantly different from zero, but is negative and significant for all other deciles. Thus, the exchange listing results we saw earlier may not be due to size alone but are probably due to sector association; companies in high-tech (growth) areas (higher proportion on NASDAQ) have more negative market reactions than low-tech companies when earnings guidance is provided.

(Insert Table 7 about here)

Table 8 shows the size-adjusted returns for announcements classified by whether they include guidance about revenues or other metrics. For simplicity and ease of exposition, we group all revenue announcements together, even if they also contain guidance about earnings-related items. All other announcements are classified as earnings, even if they refer to earnings per share, operating profits, pretax profits, etc. As can be seen from the table, revenue announcements are typically associated with stronger market reactions; whether the announcements are made with earnings or between earnings release dates. This may be due to the tendency of negative news about deteriorating operations to be framed in terms of revenues rather than earnings.

(Insert Table 8 about here)

\section{Summary and Conclusions}

This study examined market reactions to earnings guidance provided by companies subsequent to the enactment of Regulation FD, when private dissemination of 
earnings guidance to a select group of analysts was outlawed. Our results show that market participants react significantly to earnings guidance, but the reactions are much stronger when earnings guidance is provided outside of the typical earnings release period. As a matter of fact, we document insignificant reactions to disclosures made together with the earnings release.

Our results also show that market reactions are significant and in the predictable direction when companies issue a qualitative guidance without specifying a forecasted earnings or revenue figure (or a range). Furthermore, the reaction is typically stronger to revenue guidance than to earnings guidance, potentially because negative announcements during the period between earnings releases are in many cases expressed in revenue terms. Finally, we find that market reactions are stronger for larger companies and for companies that are traded on the NASDAQ, possibly because of the greater litigation risk.

The sample used in this study is constructed by using text mining techniques, which is a novel approach to analyze many text documents. Consequently, although we cover a short period of time (the post Regulation FD period), our sample is substantially larger than those used in prior studies. Thus, the results of our study are likely more generalizable to the population that a typical investor is facing. Based on our results, it seems that investors are able to process the information disclosed by companies in their earnings guidance, and react to it in the proper manner, as has been envisioned by regulators in Regulation FD. 
Table 1

Distribution of Announcements by Firms

\begin{tabular}{|c|r|r|}
\hline No. of & Median \\
Announcements & $\begin{array}{r}\text { No. of } \\
\text { Firms }\end{array}$ & $\begin{array}{r}\text { Market } \\
\text { Capitalization } \\
\text { as of 12/31/01 }\end{array}$ \\
\hline 1 & 949 & 337 \\
2 & 398 & 392 \\
3 & 205 & 667 \\
4 & 88 & 670 \\
5 & 49 & 814 \\
6 & 20 & 1800 \\
7 & 19 & 3978 \\
8 & 6 & 19600 \\
9 & 5 & 16631 \\
10 & 3 & 8215 \\
12 & 1 & 23975 \\
13 & 1 & 10210 \\
14 & 1 & 357949 \\
20 & 1 & 210401 \\
\hline
\end{tabular}


Table 2

Distribution of Firms by Industries

\begin{tabular}{|c|r|r|}
\hline SIC & $\begin{array}{r}\text { No. of } \\
\text { firms }\end{array}$ & $\begin{array}{r}\text { \% of } \\
\text { Total }\end{array}$ \\
\hline 13 & 21 & $1.2 \%$ \\
20 & 26 & $1.5 \%$ \\
27 & 24 & $1.3 \%$ \\
28 & 97 & $5.4 \%$ \\
33 & 22 & $1.2 \%$ \\
34 & 20 & $1.1 \%$ \\
35 & 143 & $8.0 \%$ \\
36 & 209 & $11.7 \%$ \\
37 & 39 & $2.2 \%$ \\
38 & 102 & $5.7 \%$ \\
48 & 63 & $3.5 \%$ \\
49 & 43 & $2.4 \%$ \\
50 & 30 & $1.7 \%$ \\
51 & 23 & $1.3 \%$ \\
56 & 27 & $1.5 \%$ \\
59 & 46 & $2.6 \%$ \\
60 & 43 & $2.4 \%$ \\
63 & 40 & $2.2 \%$ \\
73 & 398 & $22.3 \%$ \\
87 & 36 & $2.0 \%$ \\
All & 336 & $18.8 \%$ \\
Others & 1788 & $100.0 \%$ \\
\hline Total & & \\
\hline
\end{tabular}




\section{Table 3 \\ Size-Adjusted Returns and Timing of Announcement}

\begin{tabular}{|l|r|r|r|}
\hline & $\begin{array}{r}\text { Average } \\
\text { Size- } \\
\text { Adjusted } \\
\text { Return }\end{array}$ & $\mathbf{N}$ & Significance \\
\hline Guidance between earnings & $-4.7 \%$ & 1957 & 0.001 \\
announcements & $-0.5 \%$ & 1502 & 0.112 \\
Guidance with earnings release & $-2.9 \%$ & 3459 & 0.001 \\
\hline All guidance announcements & \multicolumn{2}{|c}{} \\
\hline
\end{tabular}

Notes:

1. Size-adjusted returns are calculated for the three-day window centered on the announcement date. We first calculate the cumulative return for each firm in our sample. We then calculate the equally-weighted mean cumulative return for the same size (market capitalization at the beginning of the quarter) decile. Sizeadjusted returns are the return on the company minus the return on the same size decile portfolio.

2. N represents the number of announcements.

3. Significance is the significance level obtained in a t-test that the mean sizeadjusted return is zero.

4. Guidance announcements can coincide with preliminary earnings announcements (if they are made within three days of the quarterly earnings announcement), or between earnings announcements. 


\section{Table 4 \\ Size-Adjusted Returns and Indicated Trend}

\begin{tabular}{|l|r|r|r|}
\hline Indicated Trend & $\begin{array}{r}\text { Average } \\
\text { Size- } \\
\text { Adjusted } \\
\text { Return }\end{array}$ & & \\
\hline Higher & $1.6 \%$ & 323 & Significance \\
Lower & $-7.0 \%$ & 515 & 0.025 \\
Unchanged & $-0.3 \%$ & 111 & 0.001 \\
\hline Total & $-3.3 \%$ & 949 & 0.804 \\
\hline
\end{tabular}

\section{$\underline{\text { Notes: }}$}

1. Size-adjusted returns are calculated for the three-day window centered on the announcement date. We first calculate the cumulative return for each firm in our sample. We then calculate the equally-weighted mean cumulative return for the same size (market capitalization at the beginning of the quarter) decile. Sizeadjusted returns are the return on the company minus the return on the same size decile portfolio.

2. N represents the number of announcements.

3. Significance is the significance level obtained in a t-test that the mean sizeadjusted return is zero.

4. The table reports size-adjusted returns for companies that provided guidance about the trend in their earnings (or revenues, or any other metric they used), and typically did not provide any numerical guidance (either an exact number or a range). Only 64 of the trend announcements included any quantitative data as well. 


\section{Table 5}

\section{Size-Adjusted Returns and Indicated Trend}

\begin{tabular}{|c|c|c|c|c|c|c|}
\hline \multirow[b]{2}{*}{$\begin{array}{l}\text { Indicated } \\
\text { Trend }\end{array}$} & \multicolumn{3}{|c|}{$\begin{array}{l}\text { Announcement Between Earnings } \\
\text { Reports }\end{array}$} & \multicolumn{3}{|c|}{ Guidance Together With Earnings } \\
\hline & $\begin{array}{r}\text { Average } \\
\text { Size- } \\
\text { Adjusted } \\
\text { Return } \\
\end{array}$ & $\mathbf{N}$ & Significance & $\begin{array}{r}\text { Average } \\
\text { Size- } \\
\text { Adjusted } \\
\text { Return } \\
\end{array}$ & $\mathbf{N}$ & Significance \\
\hline Higher & $1.9 \%$ & 241 & 0.030 & $0.9 \%$ & 82 & 0.491 \\
\hline Lower & $-7.4 \%$ & 444 & 0.001 & $-4.2 \%$ & 71 & 0.003 \\
\hline Unchanged & $0.6 \%$ & 80 & 0.707 & $-2.5 \%$ & 31 & 0.243 \\
\hline Total & $-3.7 \%$ & 765 & 0.001 & $-1.6 \%$ & 184 & 0.068 \\
\hline
\end{tabular}

Notes:

1. Size-adjusted returns are calculated for the three-day window centered on the announcement date. We first calculate the cumulative return for each firm in our sample. We then calculate the equally-weighted mean cumulative return for the same size (market capitalization at the beginning of the quarter) decile. Size-adjusted returns are the return on the company minus the return on the same size decile portfolio.

2. N represents the number of announcements.

3. Significance is the significance level obtained in a t-test that the mean sizeadjusted return is zero.

4. The table reports size-adjusted returns for companies that provided guidance about the trend in their earnings (or revenues, or any other metric they used), and typically did not provide any numerical guidance (either an exact number or a range).

5. The table shows separately the size-adjusted returns for companies that made their guidance announcements between earnings releases (left-most three columns) and those that provided guidance within three days of the earnings disclosure (three right-most columns). 


\section{Table 6}

\section{Size-Adjusted Returns and Exchange Listing}

\begin{tabular}{|c|c|c|c|c|c|c|}
\hline & $\begin{array}{l}\text { Announcemen } \\
\text { Reports }\end{array}$ & Betwe & en Earnings & Guidance Tog & ler Wi & h Earnings \\
\hline $\begin{array}{l}\text { Exchange } \\
\text { Listing }\end{array}$ & $\begin{array}{r}\text { Average } \\
\text { Size- } \\
\text { Adjusted } \\
\text { Return } \\
\end{array}$ & $\mathbf{N}$ & Significance & $\begin{array}{r}\text { Average } \\
\text { Size- } \\
\text { Adjusted } \\
\text { Return } \\
\end{array}$ & $\mathbf{N}$ & Significance \\
\hline $\begin{array}{l}\text { NYSE or } \\
\text { AMEX }\end{array}$ & $-2.3 \%$ & 753 & 0.001 & $0.6 \%$ & 569 & 0.075 \\
\hline NASDAQ & $-6.2 \%$ & 1204 & 0.001 & $-1.2 \%$ & 933 & 0.013 \\
\hline Total & $-4.7 \%$ & 1957 & 0.001 & $-0.5 \%$ & 1502 & 0.112 \\
\hline
\end{tabular}

Notes:

1. Size-adjusted returns are calculated for the three-day window centered on the announcement date. We first calculate the cumulative return for each firm in our sample. We then calculate the equally-weighted mean cumulative return for the same size (market capitalization at the beginning of the quarter) decile. Size-adjusted returns are the return on the company minus the return on the same size decile portfolio.

2. $\mathrm{N}$ represents the number of announcements.

3. Significance is the significance level obtained in a t-test that the mean size-adjusted return is zero.

4. The table shows separately the size-adjusted returns for companies that made their guidance announcements between earnings releases (left-most three columns) and those that provided guidance within three days of the earnings disclosure (three right-most columns). 


\section{Table 7 \\ Size-Adjusted Returns and Company Size (Market Capitalization)}

\begin{tabular}{|c|c|c|c|}
\hline Panel A: & & & \\
\hline Decile & $\begin{array}{r}\text { Average } \\
\text { Size- } \\
\text { Adjusted } \\
\text { Return } \\
\end{array}$ & $\mathbf{N}$ & Significance \\
\hline 1 (Largest) & $-1.9 \%$ & 957 & 0.001 \\
\hline 2 & $-3.1 \%$ & 605 & 0.001 \\
\hline 3 & $-4.5 \%$ & 576 & 0.001 \\
\hline 4 & $-4.2 \%$ & 464 & 0.001 \\
\hline 5 & $-3.7 \%$ & 348 & 0.001 \\
\hline 6 & $-2.8 \%$ & 240 & 0.010 \\
\hline 7 & $-0.1 \%$ & 142 & 0.942 \\
\hline 8 & $3.0 \%$ & 84 & 0.349 \\
\hline 9 & $-0.5 \%$ & 34 & 0.852 \\
\hline 10 (Smallest) & $2.8 \%$ & 9 & 0.805 \\
\hline Total & $-2.9 \%$ & 3459 & 0.001 \\
\hline
\end{tabular}

Panel B:

\begin{tabular}{|c|c|c|c|c|c|c|}
\hline \multirow[b]{2}{*}{ Decile } & \multicolumn{3}{|c|}{$\begin{array}{l}\text { Announcement Between Earnings } \\
\text { Reports }\end{array}$} & \multicolumn{3}{|c|}{ Guidance Together With Earnings } \\
\hline & $\begin{array}{r}\text { Average } \\
\text { Size- } \\
\text { Adjusted } \\
\text { Return } \\
\end{array}$ & $\mathbf{N}$ & Significance & $\begin{array}{r}\text { Average } \\
\text { Size- } \\
\text { Adjusted } \\
\text { Return } \\
\end{array}$ & $\mathbf{N}$ & Significance \\
\hline $1-2$ & $-3.5 \%$ & 947 & 0.001 & $-0.6 \%$ & 615 & 0.174 \\
\hline 3-4 & $-6.9 \%$ & 565 & 0.001 & $-1.3 \%$ & 475 & 0.016 \\
\hline $5-6$ & $-5.8 \%$ & 318 & 0.001 & $-0.4 \%$ & 270 & 0.514 \\
\hline $7-10$ & $-0.5 \%$ & 127 & 0.778 & $2.1 \%$ & 142 & 0.297 \\
\hline Total & $-4.7 \%$ & 1957 & 0.001 & $-0.5 \%$ & 1502 & 0.112 \\
\hline
\end{tabular}

Notes:

1. Decile 1 consists of companies placed in the top $10 \%$ according to market value of equity at the end of the previous quarter. Decile 10 consists of the smallest companies.

2. For other variables, see notes to Table 6 . 


\section{Table 8 \\ Size-Adjusted Returns and Metric Used in Guidance}

Panel A:

\begin{tabular}{|l|r|r|r|}
\hline Metric & $\begin{array}{r}\text { Average } \\
\text { Size- } \\
\text { Adjusted } \\
\text { Return }\end{array}$ & N & Significance \\
\hline Earnings & $-2.4 \%$ & 2029 & 0.001 \\
Revenues & $-3.5 \%$ & 1430 & 0.001 \\
\hline Total & $-2.9 \%$ & 3459 & 0.001 \\
\hline
\end{tabular}

Panel B:

\begin{tabular}{|l|r|r|r|r|r|r|}
\hline & \multicolumn{2}{|l|}{$\begin{array}{l}\text { Announcement Between Earnings } \\
\text { Reports }\end{array}$} & \multicolumn{2}{|c|}{ Guidance Together With Earnings } \\
\hline & $\begin{array}{r}\text { Average } \\
\text { Size- } \\
\text { Adjusted } \\
\text { Return }\end{array}$ & & & $\begin{array}{r}\text { Average } \\
\text { Size- } \\
\text { Adjusted } \\
\text { Return }\end{array}$ & N & Significance \\
\hline Metric & $-4.1 \%$ & 1175 & 0.001 & $-0.2 \%$ & 854 & 0.663 \\
Earnings & $-5.6 \%$ & 782 & 0.001 & $-1.0 \%$ & 648 & 0.085 \\
Revenues & $-4.7 \%$ & 1957 & 0.001 & $-0.5 \%$ & 1502 & 0.112 \\
\hline \multicolumn{1}{|c|}{ Total } & & & & & & \\
\hline
\end{tabular}

Notes:

1. The metric is what mangers use to guide investors. For simplicity, any time revenues were mentioned, the announcement is classified as revenues, even if it contains some other performance measures (such as earnings, operating profits, etc.). All other metrics are classified here as earnings, even if they refer to earnings per share, pretax profits, etc.

2. For other variables, see notes to Table 6. 


\section{References}

Cardie C. (1997). "Empirical Methods in Information Extraction”, AI Magazine, 18, \#4, pp. $65-80$.

Coller, M, and T.L. Yohn. "Management Forecasts and Information Asymmetry: An Examination of Bid-Ask Spreads" Journal of Accounting Research 35 (2) (1997): 181191.

Cowie J., and Lehnert W., "Information Extraction," Communications of the Association of Computing Machinery, vol. 39 (1), pp. 80-91.

Feldman R. and Dagan I., 1995. KDT - Knowledge Discovery in Texts. In Proceedings of the First International Conference on Knowledge Discovery, KDD-95.

Feldman R., and Hirsh H., 1996. Exploiting Background Information in Knowledge Discovery from Text. Journal of Intelligent Information Systems. 1996.

Feldman R., Aumann Y., Amir A., Klösgen W. and Zilberstien A., 1997. Maximal Association Rules: a New Tool for Mining for Keyword co-occurrences in Document Collections, In Proceedings of the 3rd International Conference on Knowledge Discovery, KDD-97, Newport Beach, CA.

Feldman R., Rosenfeld B., Stoppi J., Liberzon Y. and Schler, J., 2000. "A Framework for Specifying Explicit Bias for Revision of Approximate Information Extraction Rules". KDD 2000: 189-199.

Feldman R., Aumann Y., Liberzon Y., Ankori K., Schler J., Rosenfeld B. “A Domain Independent Environment for Creating Information Extraction Modules". CIKM 2001: 586-588.

Feldman R., Aumann Y., Finkelstein-Landau M., Hurvitz E., Regev Y., Yaroshevich. "A Comparative Study of Information Extraction Strategies". CICLing 2002: 349-359.

Heflin, F., K.R. Subramanyam., Y. Zhang. "Regulation FD and the Financial Information Environment: Early Evidence.” The Accounting Review 78 (1) (2003).

Johnson, MF, R. Kasznik, and K.K. Nelson, "The impact of securities litigation reform on the disclosure of forward-looking information by high technology firms" Journal of Accounting Research 39 (2) (2001): 297-327.

Kasznik, R., and B. Lev. "To Warn or Not to Warn: Management Disclosures in the Face of an Earnings Surprise.” Accounting Review 70 (1995): 113-134. 
Leek T. R. Information extraction using hidden Markov models. M.Sc. thesis, Dept. of Computer Science, University of Califonia, San Diego, 1997.

Miller, G. S. "Earnings Performance and Discretionary Disclosure" Journal of Accounting Research 40 (1) (2002): 173-204

Securities and Exchange Commission. "Selective Disclosure and Insider Trading." 17 CFR Parts 240, 243, and 249. Release Nos. 33-7881, 34-43154, IC-24599, File No. S7-31-99 RIN 3235-AH82

Skinner, D. "Why Firms Voluntarily Disclose Bad News." Journal of Accounting Research 32 (1994): 38-60.

Soffer, C.L., S.R. Thiagarajan and B.R. Walther. "Earnings Preannouncement Strategies." Review of Accounting Studies, 5 (2000): 5-26 